\title{
KEANEKARAGAMN FUNGI MIKORIZA ARBUSKUA (FMA) LAHAN KAMPUS UNIVERSITAS LANCANG KUNING (UNILAK)
}

\section{(Mikoriza Function Diversity Of Arbuskua (AMF) Land University Lancang Yellow Campus (UNILAK))}

\section{Ervayenri}

Dosen Fakultas Kehutanan, Universitas Lancang Kuning Jln. Yos Sudarso Km. 8 Rumbai Pekanbaru Riau Telp./Fax. (0761) 54092

Email: erva@.unilak.ac.id.

Diterima: 09 Oktober 2020, Direvisi: 21 Oktober 2020, Disetujui: 27 Oktober 2020

DOI: $10.31849 /$ forestra.v15i2.5122

\section{ABSTRACT}

Arbuscular mycorrhizal fungi (AMF) are naturally scattered and symbiotic with various tree species, AMF is able to improve plant adaptation to extreme soil conditions. About thirtyseven years Unilak, has been built in Riau Province, precisely in Rumbai Pekanbaru City. How is the existence of FMA on the developed campus land? Is the focus of this paper. Soil sampling for $A M F$ observation refers to the modified ICRAF method. The extraction of AMF spores followed the pour and wet filter method followed by centrifugation techniques. Based on the morphological characteristics of the extracted AMF spores, it was identified to the genus level. The research series showed that the presence of AMF on the Unilak campus area contained 13 types of spores from the genus Acaulospora, Gigaspora, Glomus and Sclerocystis.

Keywords: Exploration, AMF, Unilak, land

\section{ABSTRAK}

Fungi Mikoriza Arbuskula (FMA) tersebar dan bersimbiosis dengan berbagai jenis pohon secara alami, FMA mampu memperbaiki adaptasi tanaman terhadap kondisi tanah yang ekstrim. Sekitar tiga puluh tujuh tahun Unilak, telah dibangun di Propinsi Riau, tepatnya di Rumbai Kota Pekanbaru. Bagaimana keberadaan FMA pada lahan kampus yang telah dikembangkan tersebut ?, menjadi fokus bahasan paper ini. Penelitian ini bertujuan untuk menganalisis keanekaragaman FMA di lahan kampus Unilak. Pengambilan contoh tanah untuk pengamatan FMA mengacu pada metode ICRAF dengan modifikasi. Adapun ekstraksi spora FMA mengikuti metode tuang dan saring basah dilanjutkan dengan teknik sentrifugasi. Berdasarkan ciri-ciri morfologi spora FMA hasil ekstraksi, diidentifikasi sampai tingkat genus. Hasil penelitian menunjukkan bahwa keberadaan FMA pada lahan kampus Unilak terdapat 
13 tipe spora dari genus Acaulospora, Gigaspora, Glomus dan Sclerocystis. .Tidak terdapat dominansi spora FMA tertentu dan indeks kesamaan komunitasnya sedang.

Kata Kunci: Keanekaragaman, mikoriza, arbuskula, unilak

\section{PENDAHULUAN}

Jika asas pelestarian (preservation) plasma nutfah akan diterapkan secara panggah, di Indonesia maka semua hasil hutan kayu harus berasal dari hutan tanaman, sebagaimana halnya dengan pertanian yang semua hasil berasal dari tanaman. Dengan demikian hutan tanaman akan menjadi mata rantai utama penghasil kayu.

Pengelolaan unsur hara yang tepat adalah penting untuk kelestarian dan produktivitas hutan tanaman. Pengelolaan/pemanfaatan lahan yang berlebihan (terus-menerus) akan menghabiskan persediaan unsur hara tanah dalam beberapa rotasi tanaman saja dan akan menyebabkan penurunan produktivitas lahan (Mackensen 2000). Menurut Notodiningrat (2006), kendala tanah yang dihadapi dalam pembangunan hutan tanaman bersifat majemuk yang untuk penanggulangannya memerlukan teknologi sepadan yang dirancang secara cermat agar tidak justru mengusik sumber daya tanah dan lingkungan
Mackensen (2000) mengemukakan pengelolaan unsur hara menyangkut dua hal, yaitu pencegahan kehilangan unsur hara dalam jumlah besar dan penggantian/kompensasi dari kehilangan unsur hara tersebut. Jelas bahwa tidak semua penyebab kehilangan unsur hara dapat dihindarkan. Kehilangan unsur hara yang disebabkan oleh kegiatan-kegiatan pengelolaan akan selalu terjadi. Tetapi pengelolaan hutan tanaman yang tepat dapat mengatur kehilangan unsur hara secara substansial, dan karenanya dapat mempertahankan produktivitas serta menghindari biaya tambahan serendah mungkin, seperti biaya untuk pemupukan.

Secara alami lebih dari 90 persen pohon-pohonan bersimbiosis dengan FMA (Smith and Reads 1997). Eksplorasi dan identifikasi FMA dari rizosfir berbagai pohon telah dilaksanakan oleh banyak peneliti. Menurut Ervayenri (1998) hasil isolasi dan identifikasi FMA dari $50 \mathrm{~g}$ contoh tanah rizosfir HTI di lahan gambut diketahui: pada 
pohon A. crassicarpa umur 4 tahun terdapat 4.214 spora terdiri dari 10 tipe spora. Adapun pada pohon A. crassicarpa umur 1,5 tahun terdapat 5.339 spora terdiri dari 11 tipe spora. Secara keseluruhan tipe-tipe spora FMA tersebut termasuk genus Acaulospora, Entrophospora, Glomus dan Sclerocystis. Lebih jauh diungkapkan Ervayenri (1998) hasil kuantifikasi kolonisasi FMA pada akar pohon A. crassicarpa adalah 59,5\% dan jumlah propagul infektif dari hasil perhitungan dengan metoda most propable numbre 608 mengacu Sieverding (1991) dan 749 (Smith dan Dickson (1997).

Simbiosis optimum akar tanaman dengan FMA meningkatkan keefektifan (Widiastuti et al. 2002), dan serapan (Widiastuti 2007) pupuk P, berat kering tanaman dan ketahanan terhadap penyakit (Rahman dan Husin 2007) serta tinggi tanaman (Widiastuti et al. 2005). menghasilkan hormon pemacu tumbuh (Hartoyo, et al., 2011). Secara alamiah FMA telah bersimbiosis dengan akar beragam vegetasi: tanaman kelapa sawit di Jawa Barat (Widiastuti dan Kramadibrata 1993) vegatasi di lahan tercemar minyak bumi (Ervayenri
2005; 2007), lahan kritis (Husin et al. 2007) di lahan PLG Sejuta Hektar (Yuwati dan Santosa 2007) tanah salin (Nurbaity 2007), Coastal Sand Dune in Japan (Abe 2007), tanaman tebu (pulungan, 2013) dan tegakan ekaliptus (Hermawan, 2015).

Penting dan besarnya peranan FMA dalam mendukung pertumbuhan tanaman, menjadi sebab dilakukannya eksplorasi FMA yang ada dilahan kampus Unilak. Lahan kampus unilak ada seluas \pm 55 ha dengan beragam tipe tutupan lahan; hutan alam (arboretum), hutan tanaman,kebun kelapa sawit, semak belukar dan padang rumput.

Penelitian ini bertujuan untuk menganalisis keanekaragaman FMA di lahan kampus Unilak, yang beragam tipe tutupannya. Ragam tipe tutupan lahan ini diharapkan menjadi sumber keanekaragaman yang tinggi pula untuk mendapatkan FMA terseleksi nantinya.

\section{METODE PENELITIAN}

Lokasi pengambilan sampel tanah adalah lahan kampus Unilak. Sampel tanah dikoleksi dari tegakan hutan alam arboretum (HA), hutan tanaman (HT), kelapa sawit 
(KS), semak belukar (SB) dan padang rumput (PR).

Contoh tanah dan akar tumbuhan diambil pada rhizosfir perakaran tegakan. Pengambilan contoh tanah mengacu pada metode yang digunakan ICRAF (Ervayenri, 2005) dengan modifikasi. Pada tiap lokasi pengambilan contoh tanah dibuat 5 buah petak contoh (ukuran $25 \mathrm{~m} \mathrm{x} 4 \mathrm{~m}$ ), yang tersebar secara acak. Tiap petak contoh terbagi ke dalam 5 sub-petak (masingmasing $5 \mathrm{~m} \times 4 \mathrm{~m}$ ). Pada tiap sub-petak diambil contoh tanah sebanyak $400 \mathrm{~g}$ secara komposit pada zone perakaran (rhizosfir) dengan kedalaman $0-20 \mathrm{~cm}$, dan total contoh tanah yang diambil di tiap lokasi adalah $10 \mathrm{~kg}$. Contoh tanah dilabel kemudian dikemas dalam kardus serta dibawa ke laboratorium untuk analisis FMA.

Ekstraksi spora FMA dari contoh tanah dilakukan dengan mengikuti metode tuang dan saring basah (Pacioni 1992) dan dilanjutkan dengan teknik sentrifugasi (Brundrett dkk.1996). Berdasarkan ciri-ciri morfologi spora FMA hasil ekstraksi, diidentifikasi sampai tingkat marga dengan mengacu deskripsi identifikasi genus FMA
(Schenk dan Perez 1988; Brundrett dkk.1996). Spora dalam satu genus dibedakan atas beberapa tipe berdasarkan bentuk, warna dan reaksinya dengan larutan Melzer's. Pemeriksaan spora dari tiap contoh tanah dilakukan sebanyak tiga ulangan. Selain itu untuk tiap tipe spora yang diperoleh dibuat preparat mikroskopnya dengan menggunakan larutan Melzer's sebagai pewarna dan PVLG sebagai pengawet sporanya (Koske dan Testier, 1983). Selanjut dilakukan analisis terhadap spora yang diidentifikasi diantaranya:

\section{Jumlah spora}

Jumlah spora dianalisis per $100 \mathrm{~g}$ tanah contoh, berdasarkan jumlah spora yang berhasil diisolasi dari setiap tipe penggunaan Kerapatan (Densitas) spora

Kerapatan tipe spora dianalisis per $100 \mathrm{~g}$ tanah contoh, berdasarkan kelompok tipe spora sesuai lokasi lahan asal contoh tanahnya (Cox 1985).

\section{Indeks Dominansi}

Indeks dominansi (ID) diperlukan untuk memeriksa tingkat dominansi suatu tipe spora pada tiap kelompok data. Pendekatan perhitungan indeks dominansi 
yang digunakan adalah indeks dominansi Simpson (Cox 1985), dengan menggunakan rumus

$$
\text { ID }=\mathbf{C}=\sum(\mathbf{n i} / \mathbf{N})^{2}
$$

dengan pengertian : $\mathrm{C}=$ Indeks dominansi $\mathrm{ni}=$ Kerapatan suatu tipe spora

$$
\mathrm{N}=\text { Kerapatan semua }
$$

tipe spora.

\section{Indeks Keanekaragaman}

Nilai indeks keanekaragaman (IK) berguna untuk mengetahui keanekaragaman tipe spora pada setiap komunitasnya. Perhitungan nilai indeks keanekaragaman tipe spora mengikuti perhitungan indeks keanekaragaman Shannon - Weiner (Cox 1985), dengan menggunakan rumus

$$
I K=-\sum[(n i / N) \log (n i / N)]
$$

dengan pengertian : $\quad \mathrm{IK}=$ Indeks keanekaragaman ni $=$ Nilai kuantitatif suatu tipe spora

$$
\mathrm{N}=\text { Nilai kuantitatif }
$$

semua tipe spora.

\section{Indeks Kesamaan Komunitas Spora}

Indeks kesamaan komunitas (IKK) berguna untuk membandingkan kesamaan komposisi dua tipe komunitas spora. Pendekatan indeks kesamaan komunitas spora mengikuti indeks kesamaan komunitas Motyka's (Cox 1985), dengan menggunakan rumus

$$
\mathrm{IKK}=[2 \mathrm{Mw} /(\mathrm{Ma}+\mathrm{Mb})] \times 100 \%
$$
dengan pengertian :

IS = Indeks kesamaan komunitas

$\mathrm{Mw}=$ Jumlah nilai kuantitatif tipe spora pada ke dua komunitas

$\mathrm{Ma}=$ Jumlah nilai kuantitatif tipe spora pada komunitas a

$\mathrm{Mb}=$ Jumlah nilai kuantitatif tipe spora pada komunitas $b$.

\section{HASIL DAN PEMBAHASAN}

\section{Jumlah Spora}

Jumlah spora pada tegakan pohon dan vegetasi lahan kampus pada berbagai tipe penggunaan lahan bervariasi dari 127 sampai 461 spora. Hasil pengamatan jumlah spora selengkapnya terdapat dalam Tabel 1 . 
Hutan alam arboretum

Hutan tanaman

Kebun kelapa sawit

Semak belukar

Padang rumput
127

461

306

231

291
Jumlah spora pada tipe penggunaan lahan arboretum lebih sedikit, relative rendah dibanding dengan jumlah spora hasil penelitian di beberapa lahan sub optimal: lahan gambut Kalimatan Barat (Ekamawanti, et al.1994) Riau (Ervayenri, 1998), hutan bekas tebangan (Budi,1993) lahan tercemar minyak bumi (Ervayenri 2005; 2007), lahan kritis (Husin et al. 2007) lahan PLG Sejuta Hektar (Yuwati dan Santosa 2007) tanah salin (Nurbaity 2007), Coastal Sand Dune in Japan (Abe 2007). Di wilayah tropika Australia jumlah spora yang tinggi juga dijumpai pada kondisi lahan yang relatif kurang ideal seperti sekitar tambang pegunungan berbatu dan di lahan basah
(Brundrett, et al. 1996). Implikasi dari komparasi data jumlah spora ini mengindikasikan bahwa tipe penggunaan lahan arboretum masih optimal. Volk and Wheler (1984) mengungkapkan pada kondisi yang tidak menguntungkan (sub optimal) organisme secara alamiah cenderung membangun organ reproduksi seperti spora.

\section{Kerapatan (Densitas) tipe spora}

Kerapatan tipe spora dianalisis per $100 \mathrm{~g}$ tanah contoh, berdasarkan kelompok tipe spora sesuai lokasi lahan asal contoh tanahnya (Cox 1985). Hasil pengamatan kepadatan spora selengkapnya terdapat dalam Tabel 2.

Tabel 2. Kerapatan spora FMA pada $100 \mathrm{~g}$ tanah contoh lahan kampus Unilak pada berbagai tipe penggunaan lahan

\begin{tabular}{lllllll}
\hline No & Tipe & HT & KS & AR & SB & PR \\
\hline
\end{tabular}




\begin{tabular}{rlrrrrr}
\hline 1 & Glomus sp.1 & 47 & 32 & 18 & 21 & 30 \\
2 & Glomus sp.2 & 5 & 2 & 1 & 3 & 3 \\
3 & Glomus sp.3 & 6 & 3 & 0 & 0 & 5 \\
4 & Glomus sp.4 & 263 & 189 & 56 & 153 & 163 \\
5 & Glomus sp.5 & 34 & 23 & 12 & 19 & 32 \\
6 & Glomus sp.6 & 8 & 6 & 0 & 2 & 7 \\
7 & Acaulospora sp.1 & 8 & 8 & 0 & 4 & 10 \\
8 & Acaulospora sp.2 & 5 & 8 & 2 & 6 & 11 \\
9 & Acaulospora sp.3 & 2 & 1 & 0 & 0 & 0 \\
10 & Acaulospora sp.4 & 5 & 3 & 0 & 1 & 5 \\
11 & Gigaspora sp.1 & 3 & 2 & 1 & 1 & 0 \\
12 & Sclerocystis sp.1 & 11 & 7 & 9 & 3 & 6 \\
13 & Sclerocystis sp.2 & 64 & 22 & 28 & 18 & 19 \\
\hline & & 461 & 306 & 127 & 231 & 291
\end{tabular}

Pada Tabel 2, diungkapkan tiga belas tipe spora yang termasuk kedalam genus Acaulospora, Gigaspora, Glomus dan Sclerocystis berhasil diamati dalam penelitian ini. Pengamatan tipe spora berdasarkan pada bentuk, warna dan ukuran spora. Dibandingkan dengan hasil studi FMA pada tegakan A. crassicarpa di lahan gambut dengan lokasi Perawang (Ervayenri, 1998), atau lahan yang tercemar minyak bumi dengan lokasi Minas (Ervayenri, 2005) jumlah genus spora yang ditemukan lebih banyak yaitu disamping diperoleh 3 genus : Acaulospora, Gigaspora dan, Glomus, juga ditemui spora dari genus Sclerocystis. Pada 2 studi FMA di lahan gambut Kalbar juga terdapat perbedaan, pada studi 1 ditemukan spora dari genus Acaulospora, Scutellospora dan, Glomus. Pada studi 2 diperoleh spora dari 
genus Acaulospora, Entrophospora,

Scutellospora dan, Glomus (Ekamawanti, et al., 1994; Astiani dan Ekamawanti, 1996). Perbedaaan ini mungkin disebabkan oleh perbedaan ekosistem spesifiknya (Allen, et al., 1995).

Densitas spora tertinggi pada lahan kampus Unilak adalah spora dari genus Glomus. Penelitian dan isolasi FMA dari lapangan di berbagai tempat sebaran spora dari genus Glomus umumnya mempunyai densitas yang relatif tinggi dibanding genus lainnya. Penelitian Koske and Tews (1987) melaporkan bahwa densitas spora FMA pada tanah pegunungan berpasir dari New Jersey, Italy, Scotland dan Wisconsin menunjukkan bahwa densitas tertinggi terdapat pada genus Glomus, lahan perkebunan di Malaysia (Nadarajah and Nawawi, 1997) di lahan tercemar minyak bumi (Ervayenri (2005; 2007) dan lahan gambut (Ervayenri, 1998) densitas spora paling tinggi juga pada genus Glomus. Hal yang sama juga juga ditemui untuk biodiversitas FMA dibawah tegakan pohon manggis (Silviana, et al.1997)., rhizosfer tanaman jeruk (Suambai, et al. 2014), yang didominasi oleh genus Glomus. Kemungkinan besar secara alami genus Glomus memang penyebarannya sangat luas.

\section{Indeks Dominansi Indeks} Keanekaragaman

Indeks dominansi (ID) diperlukan untuk memeriksa tingkat dominansi suatu tipe spora pada tiap kelompok data. Pendekatan perhitungan indeks dominansi yang digunakan adalah indeks dominansi Simpson (Cox 1985).

Nilai indeks keanekaragaman (IK) berguna untuk mengetahui keanekaragaman tipe spora pada setiap komunitasnya. Perhitungan nilai indeks keanekaragaman tipe spora mengikuti perhitungan indeks keanekaragaman Shannon - Weiner (Cox 1985). Secara rinci nilai indeks dominansi dan indeks keanekaragaman dapat dilihat dalam Tabel 3.

Tabel 3. Nilai indeks dominansi dan keanekaragaman spora FMA pada tanah yang berasal dari lahan kampus Unilak 


\begin{tabular}{lcc}
\hline \multicolumn{1}{c}{ Tegakan/vegetasi } & Indeks Dominansi & $\begin{array}{c}\text { Indeks } \\
\text { Keanekaragaman }\end{array}$ \\
\hline Hutan alam arboretum & 0,28 & 0,71 \\
Hutan tanaman & 0.47 & 0,87 \\
Kebun kelapa sawit & 0,42 & 0.83 \\
Semak belukar & 0,33 & 0,74 \\
Padang rumput & 0,35 & 0,79 \\
\hline
\end{tabular}

Nilai indeks dominansi pada tabel 3 mengungkapkan bahwa relative tidak terdapat dominansi oleh spora FMA tertentu. Berbeda dengan nilai indeks dominansi spora FMA pada lahan sub optimal seperti tanah gambut di Kalbar genus yang dominan adalah Glomus dan Acaulospora (Ekamawanti, et al. 1994). Di wilayah tropika Australia pada areal basah, didominasi oleh genus Glomus, sedangkan areal sekitar tambang dan pegunungan berbatu didominasi oleh genus Acaulospora (Brundrett, et al. 1996). Dalam penelitian eksplorasi FMA di lahan tercemar minyak bumi juga ditemui hal yang sama. dominansi genus Glomus (12 tipe spora) dan Acaulospora (10 tipe spora) (Ervayenri. 2005; 2007).
Nilai indeks keanekaragaman spora FMA pada lahan kampus Unilak relative tinggi berkisar antara 0,71 sampai 0,87. Tingginya nilai indeks keanekaragaman ini menggambarkan individu diantara keanekaragaman tipe sporanya relatif sebanding. Hal ini sejalan dengan nilai indeks dominansi (berkorelasi negatif). Hal ini sejalan dengan kaidah ekologi secara umum yaitu tidak ada dominansi oleh spora tertentu sehingga indeks keanekaragamannya tinggi.

\section{Indeks Kesamaan Komunitas Spora}

Indeks kesamaan komunitas (IKK) berguna untuk membandingkan kesamaan komposisi dua tipe komunitas spora. Pendekatan indeks kesamaan komunitas 
spora mengikuti indeks kesamaan komunitas

Motyka's (Cox 1985). Indeks kesamaan

komunitas tipe spora hasil perhitungan

menunjukkan nilai kesamaan komunitas tipe spora tertinggi antara Hutan tanaman dengan kelapa sawit, selengkapnya disajikan dalam Tabel 4.

Tabel 4. Indeks kesamaan komunitas tipe spora spora FMA tanah yang berasal dari lahan kampus Unilak (\%)

\begin{tabular}{lcccc}
\hline \multicolumn{1}{c}{ Tegakan /vegetasi } & H.alam & HT & K.Sawit & Belukar \\
\hline Hutan tanaman & 41 & & & \\
Kelapa sawit & 46 & 72 & 53 & \\
Semak belukar & 50 & 63 & 52 & 51 \\
Padang rumput & 49 & 54 & & \\
\hline
\end{tabular}

Nilai indeks kesamaan komunitas spora FMA relative sedang dalam kisaran 41 sampai 72, dibanding dengan indeks kesamaan komunitas tegakan Acacia crassicarpa umur 4 tahun dengan umur 1 tahun dengan nilai indeks 81,59 (tinggi) yang berlokasi di Kecamatan Siak (Ervayenri, 1998). Hal ini dapat dipahami mengingat contoh tanah dikoleksi dari hamparan lahan dengan vegetasi yang berbeda. Pada hakikatnya tipikal lokasi masing-masing lahan berbeda dan hal ini akan memepengaruhi keberadaan FMA. Seperti yang diungkapkan Allen, et al. (1995), keberadaan keanekaragaman FMA berkaitan dengan ekosistem spesifiknya.

\section{KESIMPULAN DAN SARAN}

\section{A. Kesimpulan}

1. Pada lahan kampus Unilak pada berbagai tipe tutupan lahan berhasil 
diisolasi 13 tipe spora FMA yang termasuk kedalam genus Acaulospora, Gigaspora, Glomus dan Sclerocystis.

2. Tidak terdapat dominansi spora FMA tertentu Pada lahan kampus Unilak pada berbagai tipe penggunaan lahan.

3. Kesamaan komunitas spora FMA lahan kampus Unilak pada berbagai tipe penggunaan lahan sedang.

\section{B. Saran}

Disarankan untuk melakukan penelitian lajutan seleksi dan uji potensi FMA yang berasal dari lahan kampus Universitas Lancang Kuning.

\section{UCAPAN TERIMA KASIH}

Penulis menyampaikan ucapan terima kasih dan penghargaan yang tinggi kepada Fahutan Unilak, atas hibah yang diberikan dalam pendanaan penelitian ini melalui Skema penelitian utama.

\section{DAFTAR PUSTAKA}

Abe Jun-ichi P.2007 Ecology of arbuscular mycorrhizal fungi in coastal sand dune in japan Di dalam Seminar Nasional Mikoriza Percepatan
Sosialisasi Teknologi Mikoriza untuk Mendukung Revitalisasi Kehutanan, Pertanian dan Perkebunan, Bogor, 19-20 Juli 2007. IPB Bogor, Dept.Kehutanan Jakarta, AMI Bogor. Hlm. 7.

Allen, E.B., M.F. Allen, D.J. Helm, J.M. Trappe, R. Molina and E. Rincon. 1995. Patterns and regulation of mycorrhizal plant and fungal diversity. Hlm. 47-62. In. M. King. Eds. The significance and regulation of soil biodiversity. Kluwer Aca. Publ. Netherlands.

Astiani, D. dan Ekamawanti, H.A. 1996. Laporan Akhir Penelitian Kajian Sifat- Fisik, Kimia, dan Biologi Tempat Anakan Ramin (Gonystylus bancanus Kurz) Di Hutan Alam. (Tidak dipublikasikan). 77 hlm.

Brundrett M, Dells B, Grove T dan Malajczuk N. 1996. Working with mycorrhizas in forestry and agriculture. Canberra: ACIAR.

Budi, S.W. 1993. Pengaruh pembalakan hutan terhadap mikoriza dipterocarpaceae. Thesis Magister Sain PPS-IPB. Bogor. (Tidak dipublikasikan). $72 \mathrm{hlm}$.

Cox GW. 1985. Laboratory Manual of General Ecology. Ed ke-5. Dubugue, Iowa. Wm.C. Brown Publishers.

Ekamawanti HA., Rukmi I, dan Rahayu S. 
1994.

Laporan

Penelitian

Eksplorasi Keanekaragaman CMA pada Lahan Gambut. Pontianak: Univ. Tanjungpura, Badan Pengelola MIPA.

Ervayenri 1998. Studi keanekaragaman dan potensi inokulum cendawan mikoriza arbuskula (CMA) di lahan gambut (Studi kasus di Kabupaten Bengkalis Propinsi Riau). [Tesis]. Bogor: IPB, Program Pascasarjana.

Ervayenri 2005. Pemanfaatan fungi mikoriza arbuskula (FMA) dan tanaman indigenos untuk revegetasi lahan tercemar minyak bumi [Disertasi]. Bogor: IPB, Program Pascasarjana.

Ervayenri.2007. Keanekaragaman jenis fungi mikoriza arbuskula (FMA) di lahan tambang minyak bumi. Di dalam Seminar Nasional Mikoriza Percepatan Sosialisasi Teknologi Mikoriza untuk Mendukung Revitalisasi Kehutanan, Pertanian dan Perkebunan, Bogor, 19-20 Juli 2007. IPB Bogor, Dept.Kehutanan Jakarta, AMI Bogor. Hlm. 3.

Hartoyo, B., M. Ghulamahdi., L. K. Darusman., S. A. Ariz., dan I. Mansur. 2011. Keanekaragaman Fungi Mikoriza Arbuskula (FMA) Pada Rizosfer TanamanPegagan (Centella asiatica (L.)Urban.Jurnal LittriVol. 17 No. 1 : 32-40.

Hermawan H, Muin A, dan Wulandari R S,. 2015. Kelimpahan FMA pada tegakan ekaliptus (Eucalyptus pellita) berdasarkan tingkat kedalaman di lahan gambut. Jurnal Hutan Lestari. Vol. 3 (1) : 124 132

Husin EH, Rahman M, Habazar T, Auzan, Burhanudin, Zelfi Z. 2007. Observasi dan identifikasi spora cendawan mikoriza arbuskula (CMA) pada berbagai rhizosfir dilahan kritis sumatera. Di dalam Seminar Nasional Mikoriza Percepatan Sosialisasi Teknologi Mikoriza untuk Mendukung Revitalisasi Kehutanan, Pertanian dan Perkebunan, Bogor, 19-20 Juli 2007. IPB Bogor, Dept.Kehutanan Jakarta, AMI Bogor. Hlm. 4.

Koske RE. dan Testier B. 1983. A convinent permanent slide mounting medium. Mycol. Soc. Am. Newletters: 34-59.

and L.L. Tews. 1987. Vesicular arbuscular mycorrhizas fungi of Wisconsin sandy soils. Mycol., No. 79(6) : 901-905.

Mackensen J. 2000. Pengelolaan Unsur Hara pada Hutan Tanaman Industri (HTI) di Indonesia. Eschborn, Jerman. GTZ-GmbH

Nadarajah P dan Nawawi A. 1999. VAM fungi in Malaysian plantations and grassland. Dalam Seminar Internasional Mycorrhizas in sustainable Tropical Agriculture and Forest Ecosystems, Bogor. 26-30 Oktober 1997. Research and Development Centre for Biology 
LIPI - IPB - The University of Adelaide.Hlm 29. Abstr.

Notohadiningrat T 2006. Hutan Tanaman Industri dalam Tataguna Sumberdaya Lahan. Yogyakarta . Ilmu Tanah Universitas Gadjah Mada

Nurbaity A.2007. Peran cendawan mikoriza arbuskula dalam rehabilitasi lahan salin. Di dalam Seminar Nasional Mikoriza Percepatan Sosialisasi Teknologi Mikoriza untuk Mendukung Revitalisasi Kehutanan, Pertanian dan Perkebunan, Bogor, 19-20 Juli 2007. IPB Bogor, Dept.Kehutanan Jakarta, AMI Bogor. Hlm. 1.

Pacioni G. 1992. Wet sieving and decanting techniques for the extraction of spores of VA mycorrhizal fungi. Dalam : Norris, JR., Read DJ dan Varma AK, Penyunting. Methods in Microbiology. Vol. 24. San Diego: Academic Press Inc Hlm 317-322.

Pulungan, A S. 2013.Infeksi Fungi Mikoriza Arbuskula Pada Akar Tanaman Tebu (Saccharum officinarumL). Biosains Unimed/Vol.1/No.1; 4346

Rahman M, Husin EF. 2007. Aplikasi cendawan mikoriza arbuskula sebagai pupuk biologis dalam pembibitan kelapa sawit. Di dalam Seminar Nasional Mikoriza Percepatan Sosialisasi Teknologi Mikoriza untuk Mendukung
Revitalisasi Kehutanan, Pertanian dan Perkebunan, Bogor, 19-20 Juli 2007. IPB Bogor, Dept.Hut. Jakarta, AMI Bogor. Hlm. 7.

Schenk NC dan Perez Y. 1988. Manual for Identification of VA Mycorrhizal Fungi. Ed ke-2. INVAM. Gainesville: University of Florida.

Setiadi, Y. 1996. Study on biodiversity of arbuscular mycorrhizal fungi (AMF) in different land-uses system in Sumatera, Indonesia. ICRAF. Bogor.

Sieverding, E. 1988. Ecology of VA Mycorrhizal Fungi in Tropical Agroecosystems. In. Mejstrik. M, eds. Abstracts $2^{\text {nd }}$ European Symposium on Mycorrhizae. Praque, Czechoslovakia. 97 hlm.

Sieverding, E. 1991. Vesicular Arbuscular Mycorrhiza Management in Tropical Agrosystems. GTZ GmbH. Germany. $372 \mathrm{hlm}$.

Silviana, A.W. Gunawan and K. Kramadibrata. 1997. Biodiversity AMF in the rhizospheres of mangosteen. Papers Presented at the International Conference "Mycorrhizas in sustainable Tropical Agriculture and Forest Ecosystems", 26-30 Oktober 1997. Bogor, Indonesia. $4 \mathrm{hlm}$.

Smith, S. E. and S. Dickson. 1997. VA Mycorrhizas : Basic research 
techniques. Papers in Training and Workshop on Mycorrhizas, 17-30 Oktober 1997. Bogor, Indonesia. $39 \mathrm{hlm}$.

Smith S dan Reads DJ. 1997. Mycorrhizal Symbiosis. Academic Press. San Diego California.

Suambai I W, Wirawan G P dan Adiartayasa $\mathrm{W}, 2014$. Isolasi dan Identifikasi Fungi Mikoriza Arbuskular (FMA )secara Mikroskopis pada Rhizosfer Tanaman Jeruk (Citrus sp.) di Desa Kerta, Kecamatan Payangan, Kabupaten Gianyar. E-Jurnal Agroekoteknologi Tropika Vol. 3, No.4 : 201-208.

Volk, W.A. and M.F. Wheeler. 1984. Basic Mikrobiology $5^{\text {th }}$ ed. Harper \& Row, Publisher, Inc. Virginia. 396 hlm.

Widiastuti, H. dan Kramadibrata K. 1993. Identifikasi jamur mikoriza bervesikula arbuskula di beberapa kebun kelapa sawit di Jawa Barat. Menara Perkebunan, No. 61(1) : 13-19.

Widiastuti H, Sukarno N, Darusman LK, Goenadi DH, Smith S, Guhardja E. 2002. Optimasi simbiosis cendawan mikoriza arbuskula Acaulospora tuberculata dan Gigaspora margarita pada bibit kelapa sawit di tanah masam. Menara Perkebunan, 70(2): 50-57
Widiastuti H, Sukarno N, Darusman LK, Goenadi DH, Smith S, Guhardja E. 2005. Penggunaan spora cendawan mikoriza arbuskula sebagai inokulum untuk meningkatkan pertumbuhan dan serapan hara bibit kelapa sawit. Menara Perkebunan, 73(1): 26-34

Widiastuti H. 2007. Proses interaksi cendawan mikoriza arbuskula(CMA) dengan kelapa sawit. Di dalam Seminar Nasional Mikoriza Percepatan Sosialisasi Teknologi Mikoriza untuk Mendukung Revitalisasi Kehutanan, Pertanian dan Perkebunan, Bogor, 19-20 Juli 2007. IPB Bogor, Dept.Kehutanan Jakarta, AMI Bogor. Hlm. 2.

Yuwati TW, Santosa PB. 2007. Aplikasi mikoriza untuk rehabilitasi lahan rawa gambut terdegredasi. Di dalam Seminar Nasional Mikoriza Percepatan Sosialisasi Teknologi Mikoriza untuk Mendukung Revitalisasi Kehutanan, Pertanian dan Perkebunan, Bogor, 19-20 Juli 2007. IPB Bogor, Dept.Kehutanan Jakarta, AMI Bogor. Hlm. 11. 